Research Article

\title{
On the Link between the Operating Point and the Temperature Distribution in PV Arrays Working under Mismatching Conditions
}

\author{
Luigi Costanzo $(\mathbb{D})$ and Massimo Vitelli $(\mathbb{D}$ \\ Department of Engineering, Università degli Studi della Campania "Luigi Vanvitelli", Aversa, 81031 Caserta, Italy \\ Correspondence should be addressed to Luigi Costanzo; luigi.costanzo@unicampania.it
}

Received 24 July 2018; Revised 10 October 2018; Accepted 19 October 2018; Published 19 December 2018

Academic Editor: K. R. Justin Thomas

Copyright (c) 2018 Luigi Costanzo and Massimo Vitelli. This is an open access article distributed under the Creative Commons Attribution License, which permits unrestricted use, distribution, and reproduction in any medium, provided the original work is properly cited.

\begin{abstract}
Mismatching operating conditions negatively affect the extracted energy in photovoltaic (PV) systems. They may also lead to dangerous localized heating phenomena (hot spots) that can cause, in turn, accelerated ageing and reduced reliability. Since the adoption of bypass diodes or smart active switches does not prevent the occurrence of hotspots, it is necessary to investigate alternative strategies. A promising solution is represented by the proper regulation of the operating point of the PV cells in the current vs. voltage $(I-V)$ or power vs. voltage $(P-V)$ planes when mismatching conditions occur. In particular, in this paper, the existence of operating points allowing a suitable compromise between maximization of the extracted power and minimization of thermal stresses, due to hot spots, is experimentally evidenced. Experimental results highlighting the link existing between the operating point in the $I-V$ plane and the PV cell temperature distribution under uniform and mismatching operating conditions are presented and discussed. On the basis of the obtained experimental results, it is possible to state that, when mismatching conditions occur, it is mandatory to properly choose the operating point: the global maximum power point may not be the best operating point. Hence, it is crucial to gain information about the eventual occurrence of mismatching conditions in order to be able to properly choose the best operating point. Therefore, another crucial aspect that is evidenced in this paper is represented by the fact that the detection of the occurrence of mismatching conditions, based on the analysis of the shape of the $I-V$ and/or $P-V$ characteristics, is effective only if the analysis is carried out for both positive and negative voltages.
\end{abstract}

\section{Introduction}

It is well known that, in photovoltaic (PV) systems, mismatching due to partial shading, shadows of neighboring objects, dirtiness, clouds, different orientation angles of modules of the PV field, soiling, manufacturing tolerances, or ageing can cause reduced reliability and significant losses in the energy yield [1-6]. Even with the commonly used bypass diodes, mismatched cells may become reverse biased [7] and dissipate power, leading to dangerous localized heating phenomena called hot spots that in turn may cause accelerated ageing or even the damage of the cells. The hot spot in a reverse-biased PV cell occurs when its temperature increases, above the temperature of the cells surrounding it, due to power dissipation which can occur in the entire cell or a portion of it.

This increase in the cell temperature will gradually degrade the output power generated by the PV module $[8,9]$. As discussed in [4], the operating temperature of the PV modules has a huge impact on their aging. In fact, the higher the operating temperature, the higher the probability of discoloration of the encapsulant material, module delamination, creation of bubbles, and corrosion. Moreover, higher working temperatures also accelerate the degradation of the ribbon and solder bonds and the PID effect [10], as well as cause cell cracks and failures of junction boxes and bypass 
diodes. Many long-term studies made on field-aged PV generators have shown that, despite the presence of bypass diodes, localized heating phenomena represent one of the main causes of PV module failures [11-13]. On the basis of the above considerations, it is evident that it is advisable to limit as much as possible the operating temperature of PV modules. Many distributed power electronic architectures have been introduced in the literature in order to mitigate the mismatching effects (hot spots) and increase the energy yield of PV systems [14-19]. Also, the dynamical reconfiguration of PV arrays has been proposed in the literature in order to face the drawbacks that are associated to mismatching phenomena [20-25]. PV array reconfiguration can be obtained by means of a reconfigurable switch matrix made of MOSFETs or of electromechanical relays. In [26-30], it has been shown that distributed converters can improve system reliability by reducing the occurrence of hot spots. In fact, reliability represents a crucial aspect to take into account in PV applications. In [31], the following innovative concept has been introduced as concern reliability: the objective of the maximization of the energy production of a PV array during its lifetime may be in contrast with the objective of the maximization of the power production in any operating condition. That is, it may be in contrast with maximum power point tracking (MPPT) objectives, if reliability is given due consideration. Even if [31] is focused in particular on PV reconfiguration, the above concept is of course valid also when distributed power architectures are adopted. At first sight, the link existing between the reliability of a PV array and the efforts to extract its maximum possible power (MPPT) may seem to be weak. However, as shown in this paper, different PV array operating points lead to different temperature distributions, which in turn lead to different durations of life or at least to different degradation rates of the array itself [4]. Therefore, it is clear that the aging process, which is related to the PV module temperature distribution, can be accelerated or delayed by properly regulating the operating point. At this stage, the following question arises: is the MPP the best operating point in any working condition of the PV array? In this paper, it will be shown that the answer to the previous question is negative. In particular, in Section 2 the considered experimental set-up will be briefly described. In Section 3 (Section 4), experimental results highlighting the link existing between the operating point in the current vs. voltage $(I-V)$ plane and the PV cell temperature distribution under uniform (mismatching) operating conditions are presented and discussed. On the basis of these experimental results, it is possible to state that, if mismatching conditions occur, it is mandatory to properly choose the operating point: the global MPP may not be the best operating point. Therefore, it is crucial to gain information about the eventual occurrence of mismatching conditions in order to be able to properly choose the best operating point. Hence, in Section 5, it will be experimentally shown that the detection of mismatching conditions can be efficiently supported by the analysis of the shape of the $I-V$ and/or power vs. voltage $(P-V)$ characteristics not only for positive but also for negative voltages. Conclusions end the paper.
TABLE 1: Main electrical characteristics of the adopted Photonsolar PM0020 [39] Modules.

\begin{tabular}{lcc}
\hline Description & Symbol & Value \\
\hline MPP voltage & $V_{\mathrm{MPP}}$ & $16.5 \mathrm{~V}$ \\
MPP current & $I_{\mathrm{MPP}}$ & $1.21 \mathrm{~A}$ \\
MPP power & $P_{\mathrm{MPP}}$ & $20 \mathrm{~W}$ \\
Open-circuit voltage & $V_{\mathrm{OC}}$ & $20 \mathrm{~V}$ \\
Short-circuit current & $I_{\mathrm{SC}}$ & $1.38 \mathrm{~A}$ \\
Nominal operating cell temperature & $\mathrm{NOTC}$ & $45^{\circ} \mathrm{C}$ \\
Number of series cells & $N_{\mathrm{s}}$ & 36 \\
\hline
\end{tabular}

\section{The Experimental Set-up}

The main prevention method for hot spotting of PV modules is represented by passive bypass diodes that are placed in parallel with strings of PV cells. Bypass diodes turn on to provide an alternative current path and attempt to prevent extreme reverse bias voltages, and hence hot spots on PV strings. A number of long-term field studies have found that, nonetheless, hot spots still occur on systems employing bypass diodes [32-36]. Active bypass switches are an improvement over bypass diodes but do not resolve the problem [7]. There are two further methods to prevent hot spots: method 1 -regulation of the operating point (make the PV string work in open circuit in extreme cases) $[26,37,38]$ and method 2-ensure that the cell can fully dissipate the worst-case power scenario without damages [7]. For example, cells with low reverse-breakdown voltages limit the power dissipated during hot spots and may be an effective prevention method. Further studies are needed to determine the susceptibility of cells with low reverse-breakdown voltages to hot spot damages [7]. The focus of this paper is on method 1. In particular, it will be shown that once the occurrence of mismatching is detected, it is possible to reduce system degradation, increase longevity, and improve lifetime energy harvesting by properly regulating the PV operating point and the associated temperature distribution.

In the following, without any loss of generality, the results of targeted experimental activities carried out on Photonsolar PM0020 Modules [39], with the main characteristics that are reported in Table 1, will be presented and discussed.

Since Photonsolar PM0020 Modules lack bypass diodes, such modules will be called PV units (PVUs) in order to underline the fact that they are different from traditional PV modules that are equipped with bypass diodes. As a consequence, the validity of the experimental findings contained in Sections 3, 4, and 5 refers to PV modules that are not equipped with bypass diodes.

Initially, two PVUs have been simultaneously analysed. In particular, the two considered PVUs have been connected in series during the first part of the experimental campaign. Two different experimental set-ups have been considered. In Figure 1(a), the experimental set-up that has been used for tracing the $I-V$ and the $P-V$ curves of the considered PVUs is shown. In particular, such curves are obtained by means of sweeps carried out by using the IV Tracker HT 


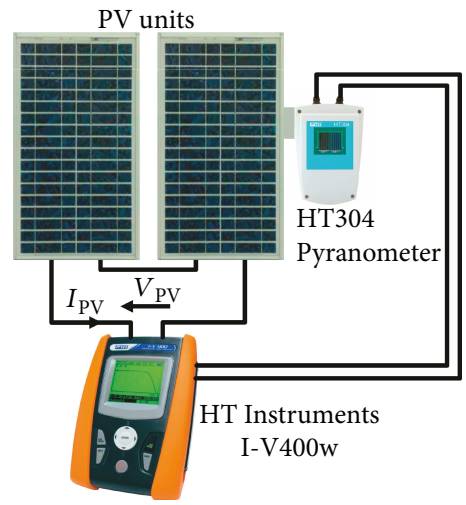

(a)

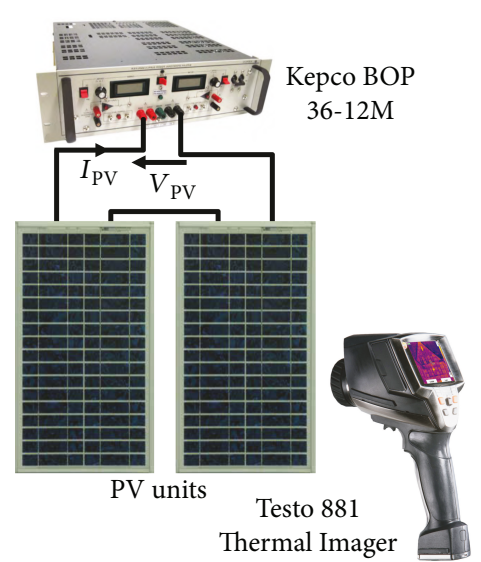

(b)

FIGURE 1: Experimental set-up adopted for (a) tracing $I-V$ and $P-V$ characteristics and (b) measuring PVU temperature as a function of the operating point.

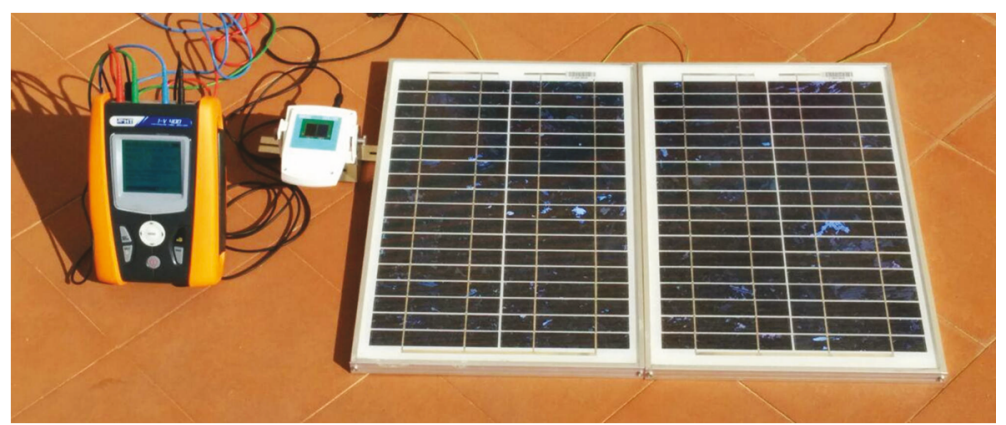

FIgUre 2: Two series-connected PVUs equipped with the IV Tracker. 26 September 2017, Aversa (CE), Italy. $S=600 \mathrm{~W} / \mathrm{m}^{2}$ and ambient temperature $T_{\mathrm{amb}}=25^{\circ} \mathrm{C}$.

Instruments I-V400w [40, 41] accompanied by the HT304 Pyranometer [40]. This is a system that is able to trace the $I-V$ and $P-V$ characteristics of PV modules or fields up to a maximum of $1000 \mathrm{~V}$ (with a voltage resolution of $0.1 \mathrm{~V}$ ) and $15 \mathrm{~A}$ (with a current resolution of $0.01 \mathrm{~A}$ ) [40]. A second experimental set-up has been adopted in order to get the temperature distribution of the considered PVUs as a function of the operating point. Such experimental set-up is shown in Figure 1(b). In particular, the desired operating point is set by means of a power supply (that fixes $V_{P V}$ ) and a thermographic image of the PVUs is obtained by means of a thermal camera [42]. The adopted power supply is a Kepco BOP 36-12M [43], a device that is able to operate in all four quadrants of the $I-V$ plane. It is a linear power supply with two bipolar selectable control channels (voltage or current mode) that are individually controllable either by front panel controls (front panel voltage or front panel current control mode) or by remote control signals (remote voltage or remote current control mode) [43]. In the considered application, the Kepco works in remote voltage control mode. The adopted thermal camera is a Testo 881 Thermal Imager whose main characteristics are the following [44]: $3.5^{\prime \prime}$ LCD display with $320 \times 240$ pixel resolution, temperature measuring range $0-350^{\circ} \mathrm{C}\left(32-662^{\circ} \mathrm{F}\right)$, accuracy $\pm 2^{\circ} \mathrm{C}$ $\left( \pm 3.6^{\circ} \mathrm{F}\right)$ or $\pm 2 \%$ of the reading (whichever is greater), reproducibility $\pm 1^{\circ} \mathrm{C}\left( \pm 1.8^{\circ} \mathrm{F}\right)$ or $\pm 1 \%$ (whichever is greater), and on-time (time to image) $30 \mathrm{~s}$.

\section{The Link between the Operating Point in the $I-V$ Plane and the PV Cell Temperature Distribution under Uniform Operating Conditions}

The first set of experimental results are characterized by the absence of mismatching conditions. In particular, a picture of the two series-connected PVUs equipped with the IV Tracker is reported in Figure 2. The tests have been carried out on 26 September 2017 in Aversa (CE), Italy $\left(40^{\circ} 57^{\prime} 56.2^{\prime \prime} \mathrm{N}, 14^{\circ} 12^{\prime} 43.2^{\prime \prime} \mathrm{E}\right)$, under a clean-sky day with an irradiance of $S=600 \mathrm{~W} / \mathrm{m}^{2}$ and an ambient temperature of $T_{\mathrm{amb}}=25^{\circ} \mathrm{C}$.

The $I-V$ and $P-V$ characteristics of the two seriesconnected PVUs have been obtained by means of the experimental set-up shown in Figure 1(a). Such curves are shown in Figures 3 and 4.

Indeed, another curve is also shown in Figure 4. It is the average temperature of the two PVUs as a function of the operating voltage. Such a curve has been obtained by means of thermographic images carried out by means of the 


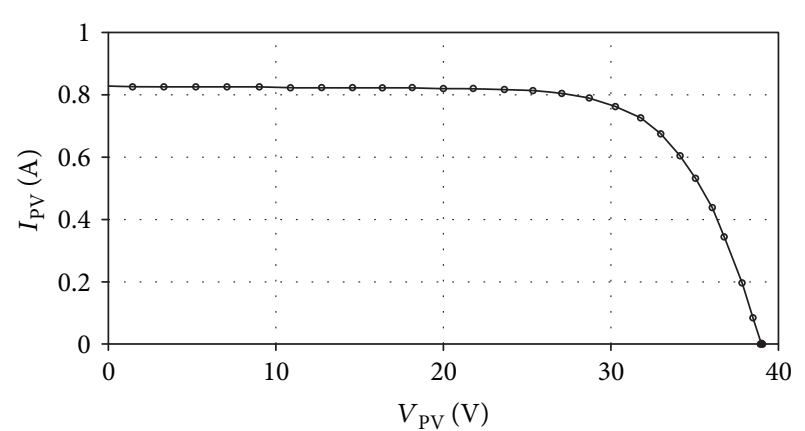

Figure 3: $I-V$ characteristic of the two series-connected PVUs. 26 September 2017, Aversa (CE), Italy. $S=600 \mathrm{~W} / \mathrm{m}^{2}$ and ambient temperature $T_{\mathrm{amb}}=25^{\circ} \mathrm{C}$.

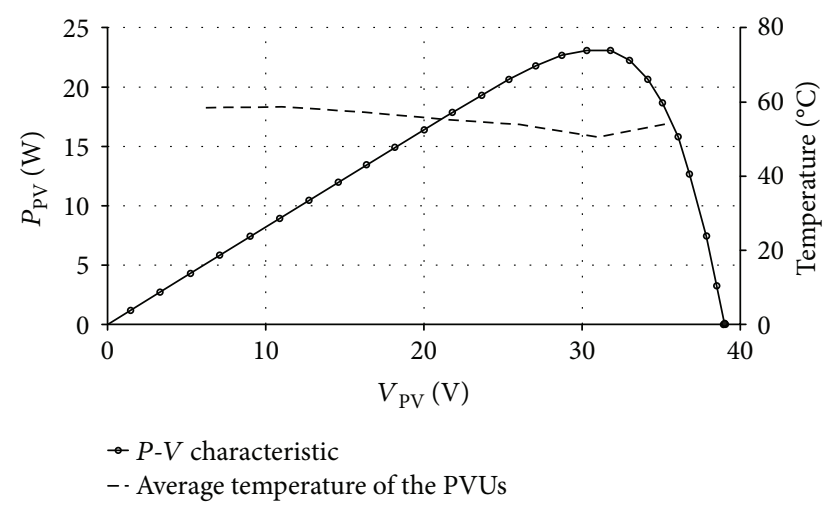

FIgURe 4: $P-V$ characteristic of the two series-connected PVUs and average temperature of the two PVUs as a function of the operating voltage. 26 September 2017, Aversa (CE), Italy. $S=600 \mathrm{~W} / \mathrm{m}^{2}$ and ambient temperature $T_{\mathrm{amb}}=25^{\circ} \mathrm{C}$.

experimental set-up shown in Figure 1(b). In particular, an example of thermographic image is shown in Figure 5. It has been obtained when the two PVUs operate in the MPP. Of course, in the absence of whatever mismatching condition, the distribution of the temperature on the two PVUs is nearly uniform. The most interesting, even if somewhat predictable, result is clearly shown by the dashed curve in Figure 4. In the absence of whatever mismatching condition, not only is the temperature distribution uniform whichever is the operating point in the $I-V$ plane, but, in the MPP it attains its minimum value $\left(50.5^{\circ} \mathrm{C}\right)$. Such a result is predictable since, when the total sun energy hitting a PV unit is more or less constant (as in the case of Figure 2 which refers to a clean-sky day), the operating point which allows extracting the maximum electrical power (that is the MPP) must be characterized by the lowest temperature. In fact, a simple analysis concerning the energetic balance of the system composed by the PVUs allows stating that, in the MPP, the energy coming from the sunlight and which remains available for the heating of the PVUs attains its minimum value just because the extracted electric energy attains its maximum value. On the other hand, in short-circuit (SC) and open-circuit (OC) conditions, the energy which is available for the heating of the PVUs attains its maximum value just because the extracted electric energy is equal to zero. Indeed, as shown in Figure 4, the difference among the value of the temperature of the PVUs in the MPP and the corresponding ones taking place in SC and/or in OC conditions is quite limited and is around $8^{\circ} \mathrm{C}$.

This is a general result. In the absence of mismatching conditions, the working of the PV system in the MPP is preferable for a two-fold reason: the maximization of the extracted power and the minimization of the aging effects that are, without exceptions, all intensified with the increase of the PV cell operating temperature [1-6]. A number of additional experimental characterizations confirming the above statement have also been carried out in different days and in different ambient operating conditions as concerns the irradiance level and the ambient temperature. They have not been reported here for the sake of brevity.

\section{The Link between the Operating Point in the $I-V$ Plane and the PV Cell Temperature Distribution under Mismatching Operating Conditions}

A similar analysis has been carried out by artificially creating a mismatching condition as shown in Figure 6. It is well known that in PV systems, mismatching can be due to partial shading, shadows of neighboring objects, dirtiness, bird droppings, leaves, snow, clouds, different orientation angles of modules of the PV field, soiling, manufacturing tolerances, or ageing [1-6]. In particular, mismatching due to moving clouds and also to other possible moving bodies is characterized by both relatively fast dynamics (short duration) and also a relatively low degree of nonuniformity as concerns cell operating conditions. Therefore, moving clouds very rarely lead to dangerous hot spot phenomena. On the other hand, dirtiness, bird droppings, leaves, snow, etc. are characterized by both a relatively long duration (indeed they require clean-up operations in order to be removed) and also a very high degree of nonuniformity as concerns cell operating conditions. Therefore, they nearly always lead to hot spot phenomena. This is the main motivation why, in the following experimental tests, mismatching conditions have been artificially induced by covering one or more cells. Firstly, a whole cell of one of the two PVUs (PVU A) has been coated with an adhesive plastic in order to partially shade such a cell. In this way, two different irradiance levels $S_{1}$ and $S_{2}$ can be identified. $S_{1}=616 \mathrm{~W} / \mathrm{m}^{2}$ characterizes the unshaded cells, and $S_{2}=145 \mathrm{~W} / \mathrm{m}^{2}$ characterizes the shaded cell. The $I-V$ and $P-V$ characteristics of the two series-connected PVUs have been obtained by means of the experimental set-up shown in Figure 1(a). Such curves are shown in Figures 7 and 8.

The presence of the two PVUs allows the simultaneous comparison, under the same weather conditions, of the temperature distribution of the PVU in mismatching operating conditions (one shaded cell) and of the identical PVU in uniform operating conditions. Such a comparison is possible by analysing Figures 9-12. Each of such figures shows the thermographic image that has been obtained in a specific operating point in the $I-V$ plane by means of the experimental arrangement depicted in Figure 1(b). Of course, every 


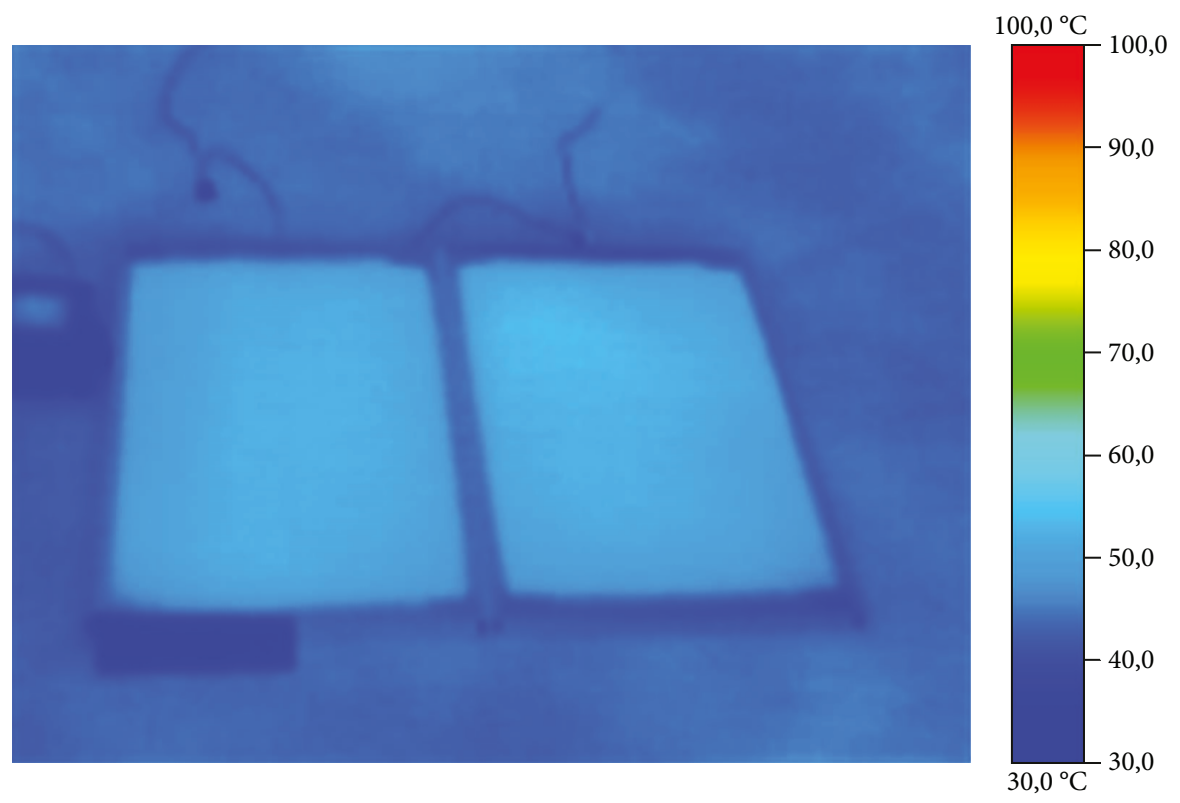

Figure 5: Thermographic image obtained when the two PVUs operate in the MPP. 26 September 2017, Aversa (CE), Italy. $S=600 \mathrm{~W} / \mathrm{m}^{2}$ and ambient temperature $T_{\mathrm{amb}}=25^{\circ} \mathrm{C}$.

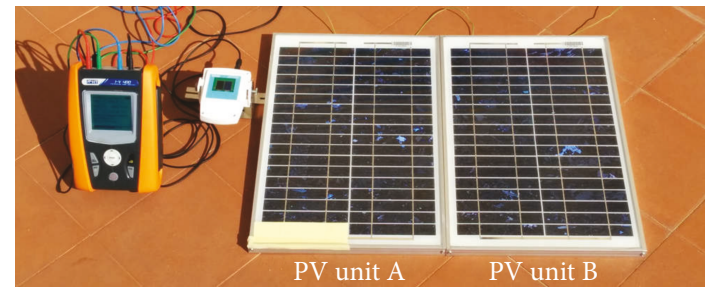

FIGURE 6: PVUs in mismatching conditions. 26 September 2017, Aversa (CE), Italy. $S_{1}=616 \mathrm{~W} / \mathrm{m}^{2}$ characterizes the unshaded cells, and $S_{2}=145 \mathrm{~W} / \mathrm{m}^{2}$ characterizes the shaded cell; $T_{\mathrm{amb}}=25^{\circ} \mathrm{C}$.

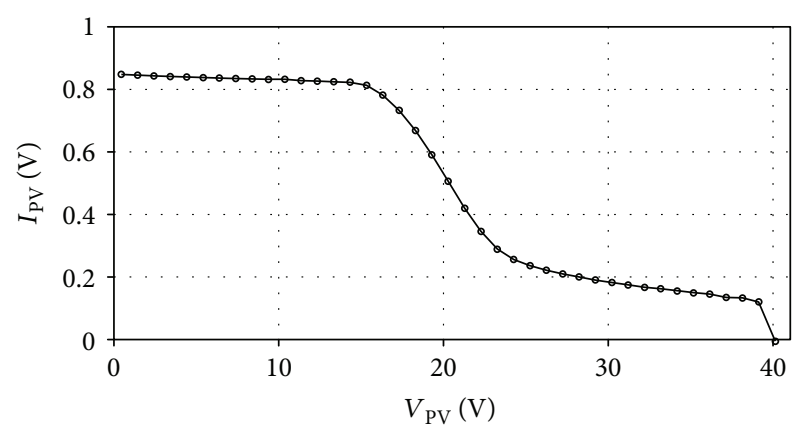

Figure 7: $I-V$ characteristic of the two series-connected PVUs. 26 September 2017, Aversa (CE), Italy. $S_{1}=616 \mathrm{~W} / \mathrm{m}^{2}$ characterizes the unshaded cells, and $S_{2}=145 \mathrm{~W} / \mathrm{m}^{2}$ characterizes the shaded cell; $T_{\mathrm{amb}}=25^{\circ} \mathrm{C}$.

thermographic image has been obtained after temporarily removing the shading plastic. The chosen operating points are the following ones: $P_{1}\left(V_{\mathrm{PV}}=11 \mathrm{~V}\right), P_{2} \quad\left(V_{\mathrm{PV}}=16 \mathrm{~V}\right.$, $\mathrm{MPP}), P_{3}\left(V_{\mathrm{PV}}=26 \mathrm{~V}\right)$, and $P_{4}\left(V_{\mathrm{PV}}=34 \mathrm{~V}\right)$. In particular, $P_{1}$ has been chosen as an example of an operating point located in the high-current region where the shaded cell is strongly reverse biased. $P_{2}$ is located at the best operating

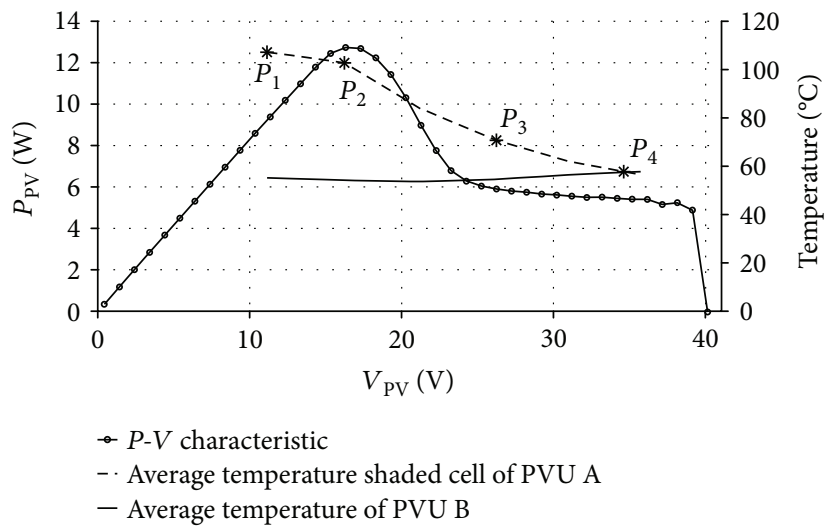

FIGURE 8: $P-V$ characteristic of the two series-connected PVUs: average temperature of the shaded cell of the PVU A and average temperature of the PVU B as a function of the operating voltage. 26 September 2017, Aversa (CE), Italy. $S_{1}=616 \mathrm{~W} / \mathrm{m}^{2}$ characterizes the unshaded cells, and $S_{2}=145 \mathrm{~W} / \mathrm{m}^{2}$ characterizes the shaded cell; $T_{\mathrm{amb}}=25^{\circ} \mathrm{C}$.

voltage from the MPPT point of view, but it is also characterized by a relatively high temperature of the shaded cell. $P_{3}$ represents an example of an operating point which allows getting a possible compromise between the extracted power and temperature level of the shaded cell. $P_{4}$ has been chosen as an example of an operating point located in the high-voltage region where the shaded cell is not reverse biased at all.

The analysis of Figures 9-12 allows drawing the following considerations. First of all, in mismatching conditions, the temperature distribution is far from being uniform. In particular, as it is well known, the PV cell region characterized by the highest temperature $T_{H}$ is just the shaded one. Many papers in the literature have put in evidence the above aspect $[2,4,31,45]$. Much less investigated instead is the strong role 


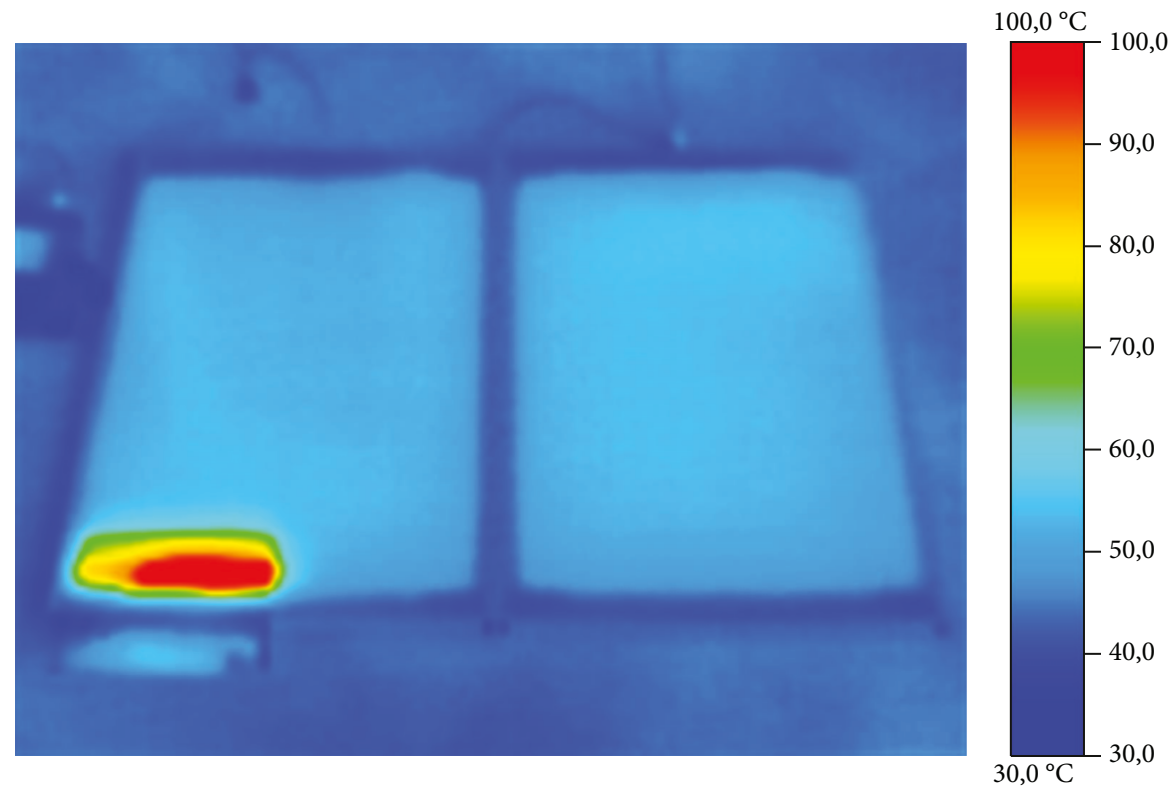

Figure 9: Thermographic image obtained when the two PVUs operate in $P_{1}\left(V_{\mathrm{PV}}=11 \mathrm{~V}\right) .26$ September 2017, Aversa (CE), Italy. $S_{1}=$ $616 \mathrm{~W} / \mathrm{m}^{2}$ characterizes the unshaded cells, and $S_{2}=145 \mathrm{~W} / \mathrm{m}^{2}$ characterizes the shaded cell; $T_{\mathrm{amb}}=25^{\circ} \mathrm{C}$.

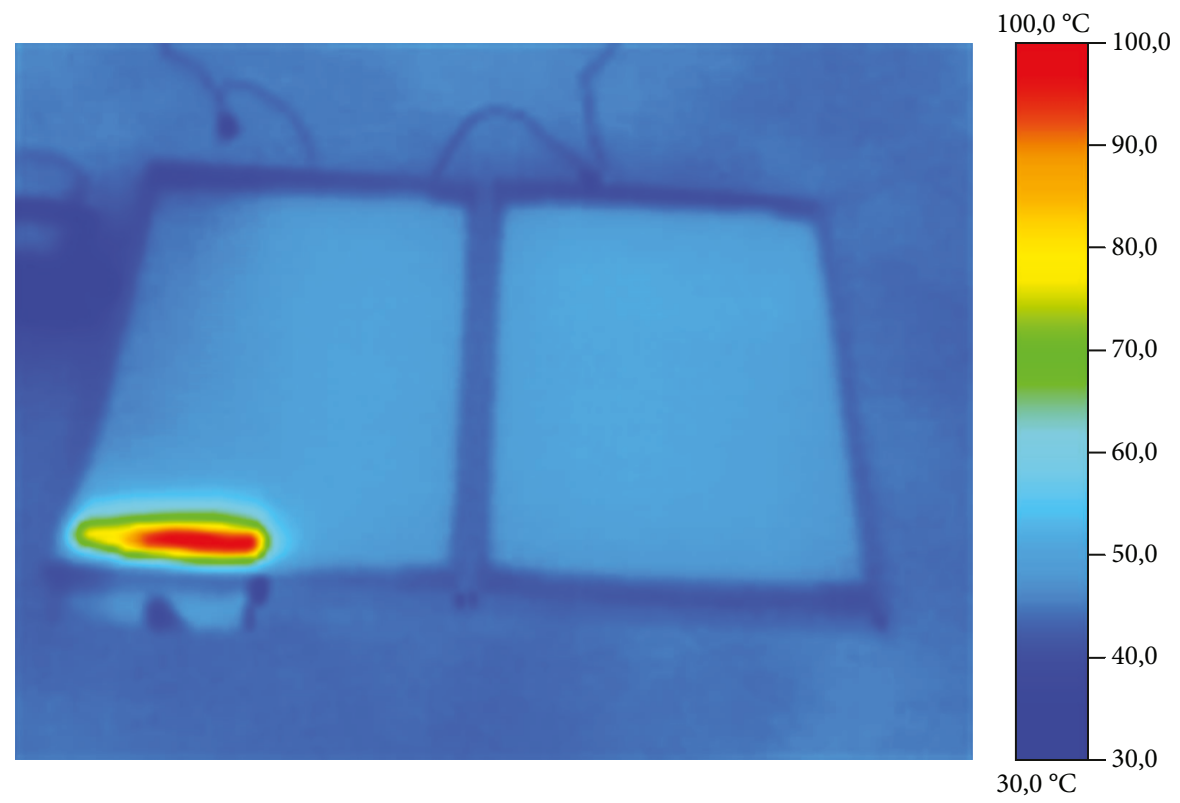

FIgURE 10: Thermographic image obtained when the two PVUs operate in $P_{2}\left(V_{\mathrm{PV}}=16 \mathrm{~V}, \mathrm{MPP}\right) .26$ September 2017, Aversa (CE), Italy. $S_{1}=616 \mathrm{~W} / \mathrm{m}^{2}$ characterizes the unshaded cells, and $S_{2}=145 \mathrm{~W} / \mathrm{m}^{2}$ characterizes the shaded cell; $T_{\mathrm{amb}}=25^{\circ} \mathrm{C}$.

played by the operating point in the $P-V$ plane. In particular, it is evident that, differently from the uniform case that has been analysed in Section 3, in the presence of mismatching the global MPP is characterized by potentially dangerous temperatures. In the considered case for example, the temperature $T_{H}$ in $P_{2}$ is equal to $100^{\circ} \mathrm{C}$.

In any case, it is possible to state that, in mismatching conditions, if reliability considerations are taken in due consideration, it may happen that the working in the MPP is to be avoided (as in the case of Figures 9-12). As an example, in the considered case, it is reasonable to operate in $P_{4}$ if any overheating is to be avoided, even if around $40 \%$ of the available electric power is wasted. Instead, a compromise (between maximization of the extracted power and minimization of localized heating phenomena) operating point is represented for example by $P_{3}$.

\section{Detection of Mismatching Operating Conditions}

As discussed in Section 4, if mismatching conditions occur, it is mandatory to properly choose the operating point since it 


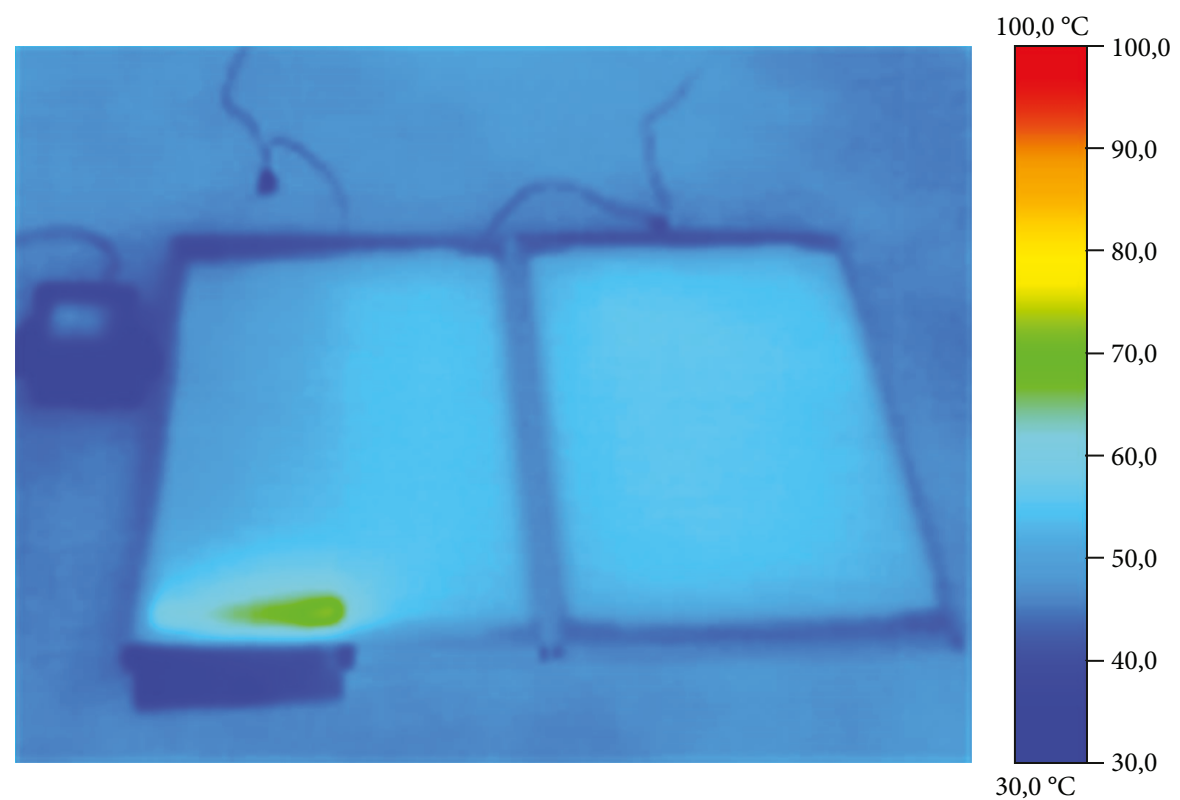

FIgure 11: Thermographic image obtained when the two PVUs operate in $P_{3}\left(V_{\mathrm{PV}}=26 \mathrm{~V}\right)$. 26 September 2017, Aversa (CE), Italy. $S_{1}=616 \mathrm{~W} / \mathrm{m}^{2}$ characterizes the unshaded cells, and $S_{2}=145 \mathrm{~W} / \mathrm{m}^{2}$ characterizes the shaded cell; $T_{\mathrm{amb}}=25^{\circ} \mathrm{C}$.

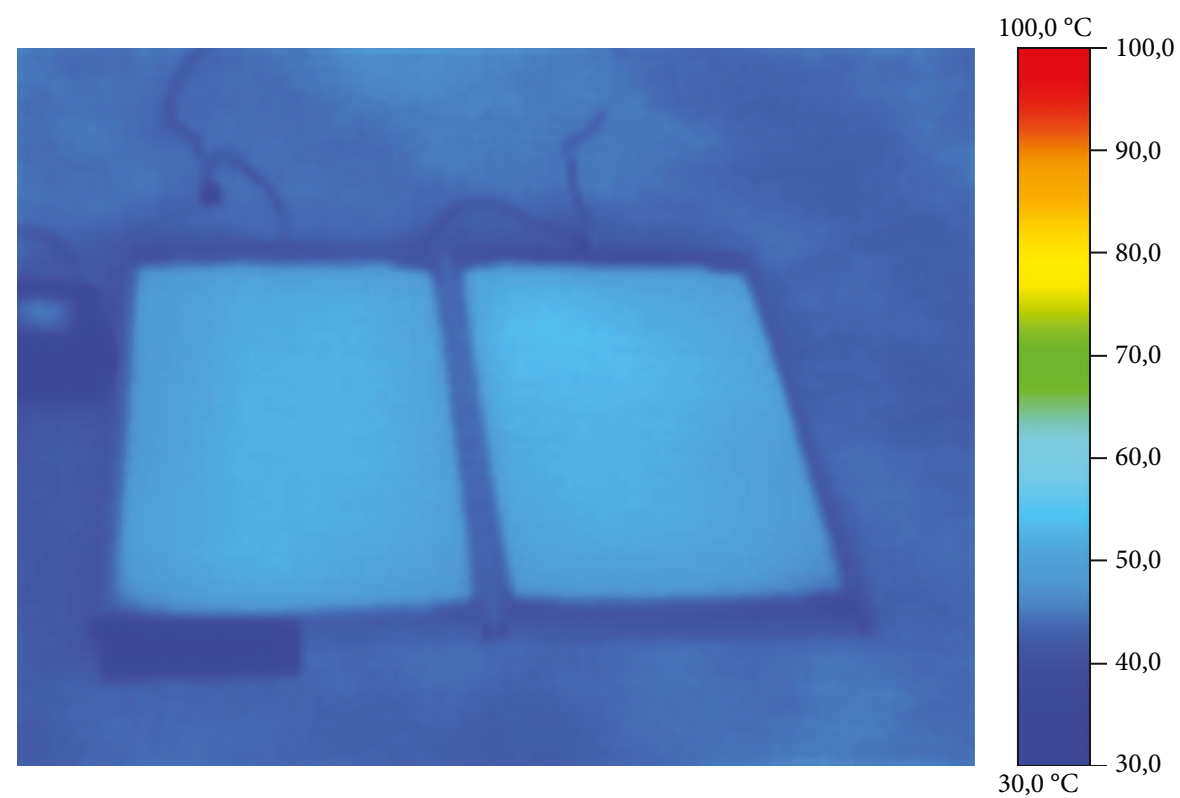

Figure 12: Thermographic image obtained when the two PVUs operate in $P_{4}\left(V_{\mathrm{PV}}=34 \mathrm{~V}\right)$. 26 September 2017, Aversa (CE), Italy. $S_{1}=616 \mathrm{~W} / \mathrm{m}^{2}$ characterizes the unshaded cells, and $S_{2}=145 \mathrm{~W} / \mathrm{m}^{2}$ characterizes the shaded cell; $T_{\mathrm{amb}}=25^{\circ} \mathrm{C}$.

frequently happens that the global MPP is not the best operating point. Hence, it is crucial to develop robust techniques able to provide accurate information on the eventual occurrence of mismatching conditions (mismatching detection). Such techniques cannot do without the analysis of the shape of the $I-V$ and/or $P-V$ characteristics. Many papers in the literature have been devoted to such an analysis (that is carried out by analysing the shape of the $I-V$ and/or $P-V$ characteristics for positive voltages). The analysis is nearly always coupled with the adoption of irradiance and/or temperature sensors [46-50]. The accuracy of the mismatching detection is strongly related to the capillarity of the distribution of the adopted sensors. It is worth noting that, for economic and practical reasons, of course only a limited number of sensors can be used in practical PV applications. Therefore, the possibility of mismatching detection errors is real. In this section, it will be shown that the mismatching detection can be efficiently supported by the analysis of the shape of the $I-V$ and/or $P-V$ characteristics that has to be carried out not only for positive but also for negative voltages. In other words, the probability of mismatching detection errors cannot be strongly decreased unless the shape of the $I-V$ and/or $P-V$ 


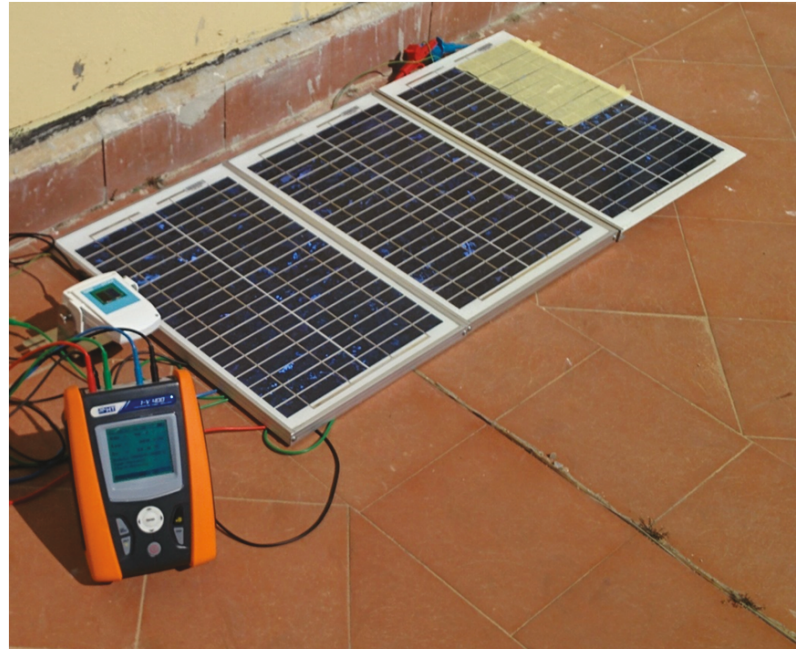

Figure 13: Three series-connected PVUs equipped with the IV Tracker. 27 September 2017, Aversa (CE), Italy. $S_{1}=775 \mathrm{~W} / \mathrm{m}^{2}$ characterizes the unshaded cells, and $S_{2}=180 \mathrm{~W} / \mathrm{m}^{2}$ characterizes the shaded cells; $T_{\mathrm{amb}}=26^{\circ} \mathrm{C}$.

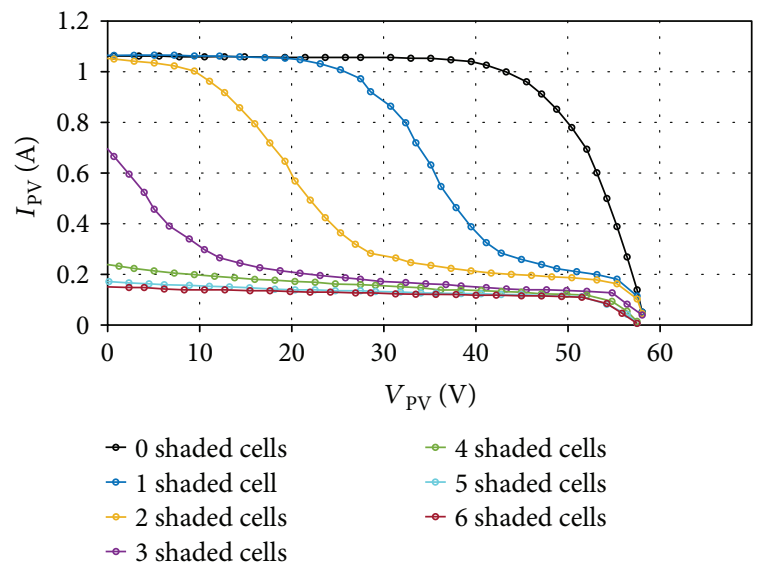

FIgURE 14: $I-V$ characteristics of the three series-connected PVUs with a growing number of shaded cells. 27 September 2017, Aversa (CE), Italy. $S_{1}=775 \mathrm{~W} / \mathrm{m}^{2}$ characterizes the unshaded cells, and $S_{2}=180 \mathrm{~W} / \mathrm{m}^{2}$ characterizes the shaded cells; $T_{\mathrm{amb}}=26^{\circ} \mathrm{C}$.

characteristics for negative voltages is properly taken into account. The following results have been obtained by adopting the experimental set-up of Figure 1(a) but with three instead of two PVUs, as shown in Figure 13. In particular, a growing number of cells have been coated with an adhesive plastic in order to partially shade them. In this way, two different irradiance levels $S_{1}$ and $S_{2}$ have been identified. $S_{1}=775 \mathrm{~W} / \mathrm{m}^{2}$ characterizes the unshaded cells, and $S_{2}=180 \mathrm{~W} / \mathrm{m}^{2}$ characterizes the shaded cells. The corresponding $I-V$ and $P-V$ characteristics are shown in Figures 14 and 15.

From Figures 14 and 15, it is evident that the knee point in the $I-V$ plane progressively moves towards the second quadrant as long as the number of shaded cells increases. In the cases of 1 and 2 shaded cells, two maxima appear in the $P-V$ curve, while in the remaining cases only one MPP is

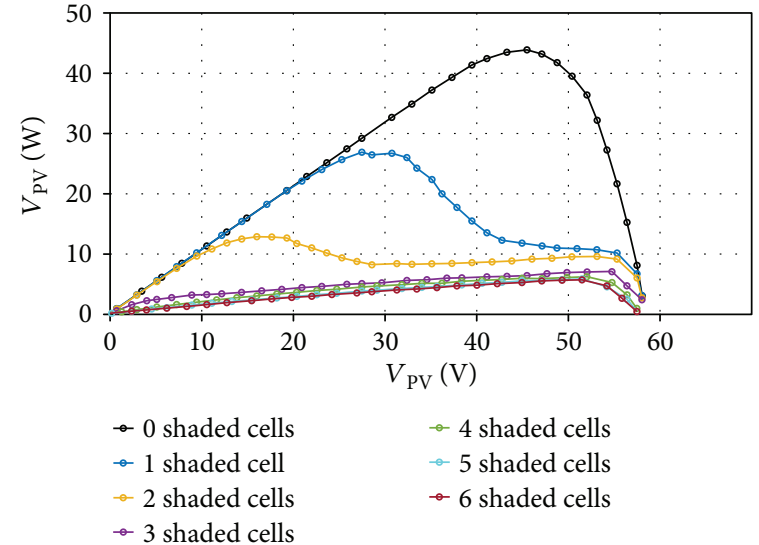

Figure 15: $P-V$ characteristics of the three series-connected PVUs with a growing number of shaded cells. 27 September 2017, Aversa (CE), Italy. $S_{1}=775 \mathrm{~W} / \mathrm{m}^{2}$ characterizes the unshaded cells, and $S_{2}=180 \mathrm{~W} / \mathrm{m}^{2}$ characterizes the shaded cells; $T_{\mathrm{amb}}=26^{\circ} \mathrm{C}$.

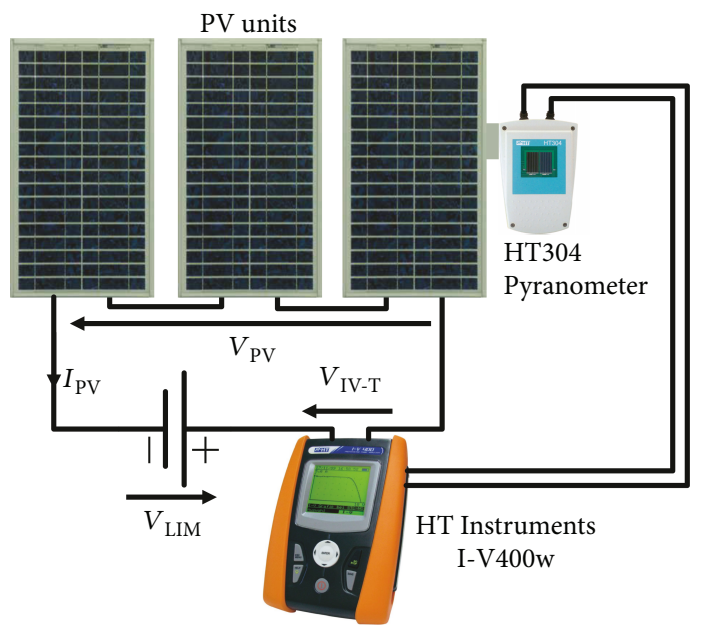

FIgURE 16: Experimental set-up adopted for tracing $I-V$ and $P-V$ characteristics both for positive and negative voltages.

present. In particular, the global MPP is located at low voltages for the $P-V$ curves corresponding to 0,1 , and 2 shaded cells and at high voltages for the remaining cases. An important aspect to underline is that, the mere analysis of the $I-V$ and/or of the $P-V$ characteristics for positive voltages only, does not allow mismatching detection in the case where the number of shaded cells is greater than 2 . Hence, in such cases, it is necessary to extend the analysis by including also the second quadrant of the $I-V$ plane (negative voltages). In order to get the sweep of the characteristics not only for positive but also for negative voltages, it has been necessary to adopt the experimental set-up that is schematically shown in Figure 16.

It has been necessary to employ the battery pack $\left(V_{\text {LIM }}\right)$ because the adopted IV Tracker (HT Instruments I-V400w) is able to trace $I-V$ and $P-V$ characteristics only for positive voltages [40]. In practice, the following equality holds:

$$
V_{\mathrm{PV}}=V_{\mathrm{IV}-\mathrm{T}}-V_{\mathrm{LIM}},
$$




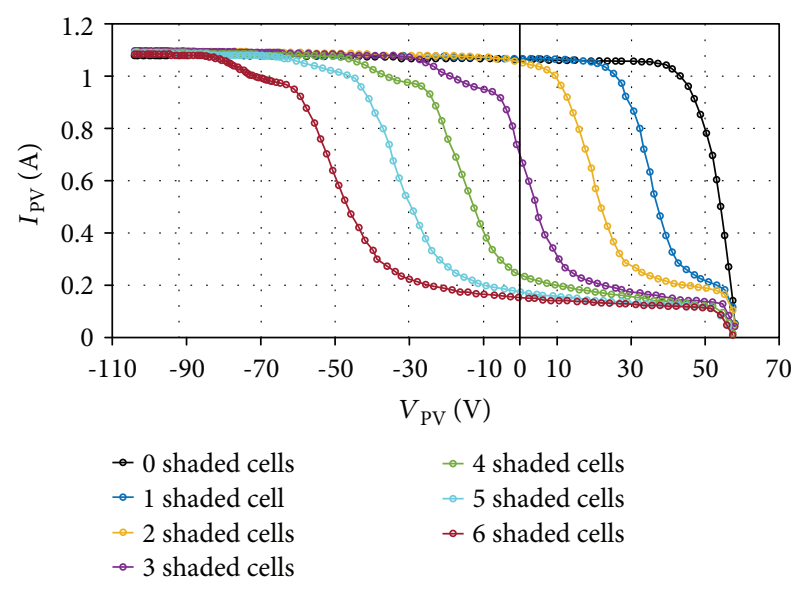

FIGURE 17: Full version (for both positive and negative voltages) of the $I-V$ characteristics of the three series-connected PVUs with a growing number of shaded cells. 27 September 2017, Aversa (CE), Italy. $S_{1}=775 \mathrm{~W} / \mathrm{m}^{2}$ characterizes the unshaded cells, and $S_{2}=180$ $\mathrm{W} / \mathrm{m}^{2}$ characterizes the shaded cells; $T_{\mathrm{amb}}=26^{\circ} \mathrm{C}$.

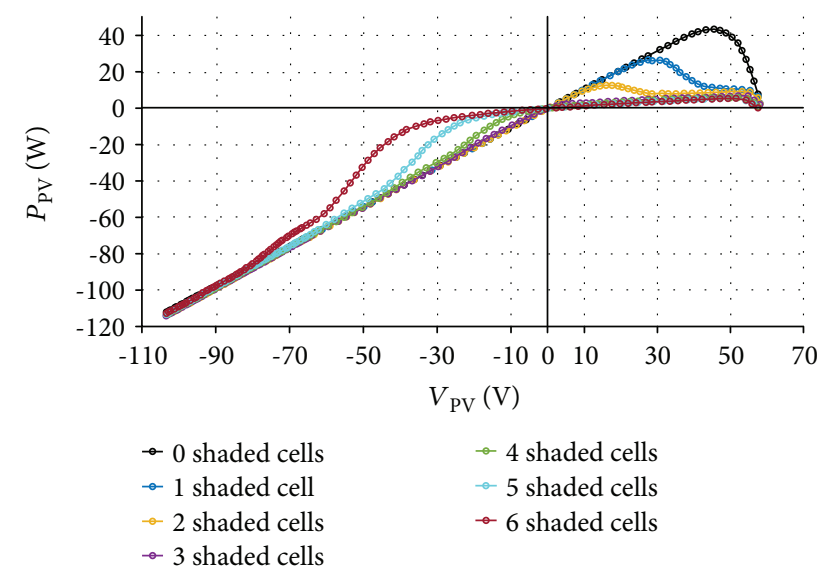

FIGURE 18: Full version (for both positive and negative voltages) of the $P-V$ characteristics of the three series-connected PVUs with a growing number of shaded cells. 27 September 2017, Aversa (CE), Italy. $S_{1}=775 \mathrm{~W} / \mathrm{m}^{2}$ characterizes the unshaded cells, and $S_{2}=180$ $\mathrm{W} / \mathrm{m}^{2}$ characterizes the shaded cells; $T_{\mathrm{amb}}=26^{\circ} \mathrm{C}$.

where $V_{\text {LIM }} \approx 106 \mathrm{~V}$. Hence, it is possible to keep the output voltage $V_{\text {IV-T }}$ of the IV Tracker for positive values (in fact it is able to trace the $I-V$ and $P-V$ characteristics only from $0 \mathrm{~V}$ up to a maximum of $1000 \mathrm{~V}$ [40]) while allowing $V_{\mathrm{PV}}$ to assume negative values. In particular, the minimum allowed negative value that can be assumed by $V_{\mathrm{PV}}$ is equal to $-V_{\text {LIM }}$.

Figures 17 and 18, respectively, represent the full versions (for both positive and negative voltages) of the $I-V$ and the $P-V$ characteristics of Figures 14 and 15 .

The analysis of Figures 14, 15, 17, and 18 clearly reveals that the inclusion of negative voltages allows the mismatching detection (based on the detection of knees or on the analysis of the shape of the characteristics) also for the cases corresponding to a number of shaded cells that are greater than 2 .

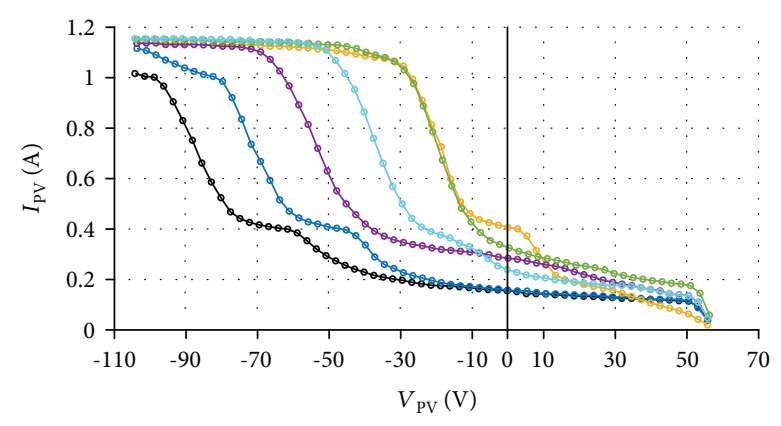

$$
\begin{array}{ll}
\rightarrow N_{1}=100, N_{2}=7, \text { and } N_{3}=1 & \rightarrow N_{1}=102, N_{2}=3 \text {, and } N_{3}=3 \\
\rightarrow N_{1}=101, N_{2}=6, \text { and } N_{3}=1 & \rightarrow N_{1}=104, N_{2}=2 \text {, and } N_{3}=2 \\
\rightarrow N_{1}=104, N_{2}=3 \text {, and } N_{3}=1 & \rightarrow N_{1}=103, N_{2}=2 \text {, and } N_{3}=3
\end{array}
$$

FIGURE 19: Full version (for both positive and negative voltages) of the $I-V$ characteristics of the three series-connected PVUs with different numbers of shaded cells. 27 September 2017, Aversa (CE), Italy. $S_{1}=841 \mathrm{~W} / \mathrm{m}^{2}, S_{2}=198 \mathrm{~W} / \mathrm{m}^{2}$, and $S_{3}=330 \mathrm{~W} / \mathrm{m}^{2}$; $T_{\mathrm{amb}}=27^{\circ} \mathrm{C}$.

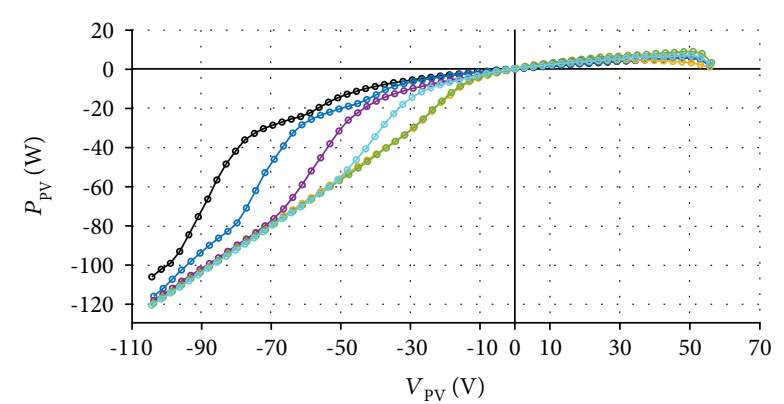

$$
\begin{array}{ll}
\rightarrow N_{1}=100, N_{2}=7 \text {, and } N_{3}=1 & \rightarrow N_{1}=102, N_{2}=3 \text {, and } N_{3}=3 \\
\rightarrow N_{1}=101, N_{2}=6 \text {, and } N_{3}=1 & \rightarrow N_{1}=104, N_{2}=2 \text {, and } N_{3}=2 \\
\rightarrow N_{1}=104, N_{2}=3 \text {, and } N_{3}=1 & \rightarrow N_{1}=103, N_{2}=2 \text {, and } N_{3}=3
\end{array}
$$

Figure 20: Full version (for both positive and negative voltages) of the $P-V$ characteristics of the three series-connected PVUs with different numbers of shaded cells. 27 September 2017, Aversa (CE), Italy. $S_{1}=841 \mathrm{~W} / \mathrm{m}^{2}, S_{2}=198 \mathrm{~W} / \mathrm{m}^{2}$, and $S_{3}=330 \mathrm{~W} / \mathrm{m}^{2}$; $T_{\mathrm{amb}}=27^{\circ} \mathrm{C}$.

Obviously, the mismatching detection based on the analysis of the shape of the characteristics also for negative voltages is affected by the following limitations. Bringing cell operating points in the second quadrant (negative voltages) may cause their breakdown [51]. Therefore, in order to avoid permanent damages to the cells, the value of $V_{\text {LIM }}$ must be limited on the basis of the physical characteristics of the adopted cells. However, it is worth noting that, obviously, the analysis in the second quadrant is possible only for $V_{\mathrm{PV}} \geq-V_{\text {LIM }}$. Hence, should the knees be located at voltages $V_{\mathrm{PV}} \ll-V_{\text {LIM }}$ mismatching detection can be carried out with the help of a number of irradiance sensors.

Moreover, the mismatching detection based on the monitoring of the $I-V$ module characteristic also for negative voltages, unavoidably leads to the necessity of the substitution of the usual bypass diodes with suitable "smart" bypass diodes to be implemented with active switches. The use of "smart" bypass diodes has multiple functions. In fact, "smart" bypass diodes allow not only the characterization 


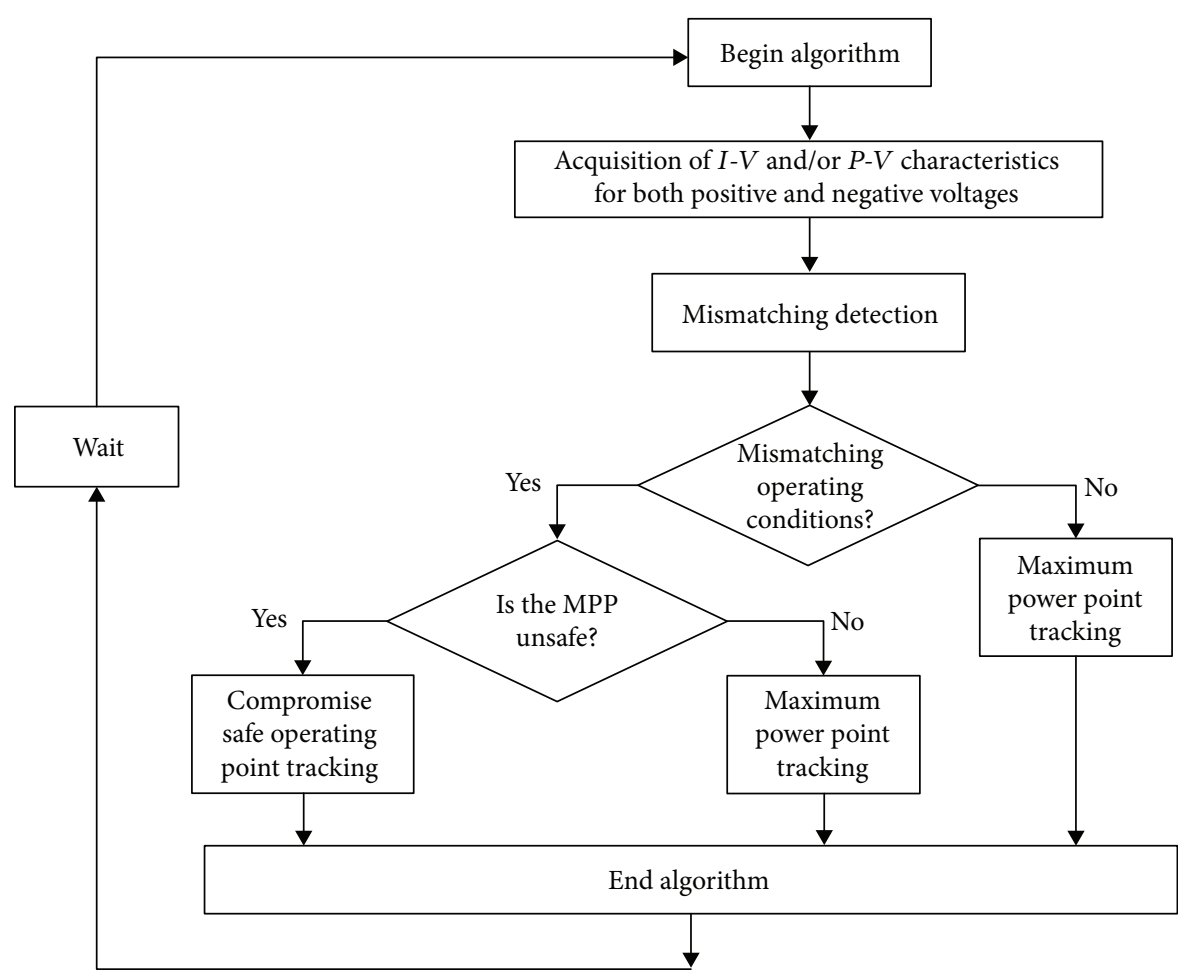

FIGURE 21: Flow chart example of an algorithm aimed at identifying a proper operating point allowing a suitable compromise between maximization of extracted power and minimization of thermal stresses.

of PV modules for negative voltages ("smart" bypass diode off) but also the possibility of controlling the value of the voltage in correspondence to which the "smart" bypass diode must be turned on. Such a function can be beneficial in terms of controlling the severity of reverse bias voltage values on the shaded cells, and therefore in terms of controlling losses (and hence of temperatures). The control of the above losses means the control of the associated increase of the cell temperature that can reach, in extreme cases, $500^{\circ} \mathrm{C}[13,52,53]$.

Furthermore, it is worth noting that, of course, the voltage sweeps of the characteristics of the PV modules not only for positive but also for negative voltages must be as fast as possible (depending on the value assumed by the cell's capacitance). The repetition frequency of the sweep must be customized on the basis of the considered application. As an example, if it is known that surrounding objects may project a shadow during a given interval of time of the day, the sweep could be carried out much more frequently just during such an interval of time. Of course, the adopted frequency must be a compromise between contrasting requirements. The higher the repetition frequency, the higher the robustness of the diagnostic. Nevertheless, at the same time, the higher the repetition frequency, the higher the energy losses due to the lack of production during sweep operations.

It is worth noting that Figures $14,15,17$, and 18 refer to a scenario in which only two different irradiance levels $S_{1}$ and $S_{2}$ can be identified. $S_{1}=775 \mathrm{~W} / \mathrm{m}^{2}$ characterizes the unshaded cells, and $S_{2}=180 \mathrm{~W} / \mathrm{m}^{2}$ characterizes the shaded cells. Further tests have been carried out by using the experimental set-up of Figure 16 but with three different irradiance levels $S_{1}=841 \mathrm{~W} / \mathrm{m}^{2}, S_{2}=198 \mathrm{~W} / \mathrm{m}^{2}$, and $S_{3}=$ $330 \mathrm{~W} / \mathrm{m}^{2}$, obtained with different types of coating plastics. The corresponding $I-V$ and $P-V$ characteristics, obtained both for positive and negative voltages, are shown in Figures 19 and 20. In such figures, $N_{1}$ indicates the number of cells characterized by an irradiance level $S_{1}, N_{2}$ the number of cells characterized by an irradiance level $S_{2}$, and $N_{3}$ the number of cells characterized by an irradiance level $S_{3}$. Also in this scenario, it is evident that in some cases the mismatching detection based on the analysis of the shape of the $I-V$ and/or $P-V$ characteristics is possible only by including negative voltages.

The above considerations can be profitably exploited as explained in the sequel. In particular, in Figure 21, a flow chart example of an algorithm aimed at identifying a proper operating point that allows getting a suitable compromise between the maximization of extracted power and minimization of thermal stresses is reported. In such a figure, the main steps that should be followed are evidenced. First of all, the algorithm should perform the acquisition of the $I-V$ and/or $P-V$ characteristics of PV modules for both positive and negative voltages. On the basis of such curves (and, if necessary, with the help of additional irradiance and/or temperature sensors) the mismatching detection can be carried out. Hence, if mismatching conditions are not present, a classical MPPT algorithm can be carried out. If, instead, mismatching conditions are detected it means that, depending on the considered case, the MPP could be an unsafe operating point from the thermal stresses' point of view. In such a case, the tracking of a compromise safe operating point different from the MPP must be carried out. 
The detailed design of a solution for the identification of the optimal compromise safe operating point is beyond the objectives of this paper. Further work is in progress on such an aspect. In particular, the identification algorithm that has been proposed in [31] can be considered as a first attempt of identification of a compromise safe operating point. In fact, in [31], with specific reference to the series parallel PV array architecture, it is shown that, by means of the reconfiguration of the PV module connections and with the help of a proper objective function, it is possible to identify, in any operating condition, both the optimal array configuration and the associated optimal operating point that are able to lead to the maximization of the extracted energy during the whole PV array lifetime.

\section{Conclusions}

Since the adoption of bypass diodes or smart active switches does not prevent the occurrence of hotspots in PV applications, it is necessary to investigate alternative possibilities. A promising solution is represented by the proper regulation of the operating point of the PV cells in the $I-V$ plane when mismatching conditions occur. In this paper, the existence of operating points allowing a suitable compromise between the maximization of the extracted power and minimization of thermal stresses has been experimentally evidenced. The main conclusion that can be drawn is that, during the life of a PV system, it is certainly preferable to give up a part of the available energy if it is possible to gain greater energy in the future. Therefore, situations exist in which MPPT is to be avoided, especially when it is obtained at the price of too high and dangerous thermal stresses that will certainly lead to the accelerated derating of the PV array due to accelerated aging or, in extreme cases, to its premature failure. Of course, the proper regulation of the operating point is strictly related to the robust detection of the occurrence of mismatching conditions. Therefore, another crucial aspect that has been evidenced, in this paper, is represented by the fact that the mismatching detection based on the analysis of the shape of the $I-V$ and/or $P-V$ curves is effective only if the sweep of the characteristics is carried out both for positive and negative voltages. The authors feel that the best strategy in order to avoid or limit the occurrence of hotspots and of their associated drawbacks is represented by the combined use of a careful regulation of the operating point (which does not always mean MPPT) coupled with the adoption of PV cells with low reverse-breakdown voltages able to intrinsically limit the power dissipated during hot spots.

\section{Data Availability}

All the data used to support the findings of the paper are included within the article.

\section{Conflicts of Interest}

The authors declare that there is no conflict of interest regarding the publication of this paper.

\section{References}

[1] G. Makrides, B. Zinsser, M. Schubert, and G. E. Georghiou, "Performance loss rate of twelve photovoltaic technologies under field conditions using statistical techniques," Solar Energy, vol. 103, pp. 28-42, 2014.

[2] W. B. Xiao, F. Y. Hu, H. M. Zhang, and H. M. Wu, "Experimental investigation of the effects of partial shading on photovoltaic cells' electrical parameters," International Journal of Photoenergy, vol. 2015, Article ID 191603, 7 pages, 2015.

[3] J. Guerrero, Y. Muñoz, F. Ibáñez, and A. Ospino, "Analysis of mismatch and shading effects in a photovoltaic array using different technologies," IOP Conference Series: Materials Science and Engineering, vol. 59, no. 1, article 012007, 2014.

[4] P. Manganiello, M. Balato, and M. Vitelli, "A survey on mismatching and aging of PV modules: the closed loop," IEEE Transactions on Industrial Electronics, vol. 62, no. 11, pp. 7276-7286, 2015.

[5] M. A. Chaaban, L. El Chaar, and M. Alahmad, "An adaptive photovoltaic topology to overcome shading effect in PV systems," International Journal of Photoenergy, vol. 2015, Article ID 294872, 9 pages, 2015.

[6] W. He, F. Liu, J. Ji, S. Zhang, and H. Chen, "Safety analysis of solar module under partial shading," International Journal of Photoenergy, vol. 2015, Article ID 907282, 8 pages, 2015.

[7] K. A. Kim and P. T. Krein, "Reexamination of photovoltaic hot spotting to show inadequacy of the bypass diode," IEEE Journal of Photovoltaics, vol. 5, no. 5, pp. 1435-1441, 2015.

[8] M. Dhimish, V. Holmes, B. Mehrdadi, M. Dales, and P. Mather, "Output-power enhancement for hot spotted polycrystalline photovoltaic solar cells," IEEE Transactions on Device and Materials Reliability, vol. 18, no. 1, pp. 37-45, 2018.

[9] M. Simon and E. L. Meyer, "Detection and analysis of hot-spot formation in solar cells," Solar Energy Materials and Solar Cells, vol. 94, no. 2, pp. 106-113, 2010.

[10] V. Naumann, D. Lausch, A. Hähnel et al., "Explanation of potential-induced degradation of the shunting type by $\mathrm{Na}$ decoration of stacking faults in Si solar cells," Solar Energy Materials and Solar Cells, vol. 120, pp. 383-389, 2014.

[11] S. Kaplanis and E. Kaplani, "Energy performance and degradation over 20 years performance of BP c-Si PV modules," Simulation Modelling Practice and Theory, vol. 19, no. 4, pp. 1201-1211, 2011.

[12] H. Ziar, S. Mansourpour, E. Afjei, and M. Kazemi, "Bypass diode characteristic effect on the behavior of solar PV array at shadow condition," in 2012 3rd Power Electronics and Drive Systems Technology (PEDSTC), pp. 229-233, Tehran, Iran, February 2012.

[13] M. Köntges, S. Kurtz, C. Packard et al., Performance and Reliability of Photovoltaic Systems, Subtask 3.2: Review of Failures of Photovoltaic Modules, IEA PVPS Task 13, External final report IEA-PVPS, International Energy Agency, Photovoltaic Power Systems Programme, 2014.

[14] N. Femia, G. Lisi, G. Petrone, G. Spagnuolo, and M. Vitelli, "Distributed maximum power point tracking of photovoltaic arrays: novel approach and system analysis," IEEE Transactions on Industrial Electronics, vol. 55, no. 7, pp. 2610-2621, 2008.

[15] S. M. MacAlpine, R. W. Erickson, and M. J. Brandemuehl, "Characterization of power optimizer potential to increase energy capture in photovoltaic systems operating under 
nonuniform conditions," IEEE Transactions on Power Electronics, vol. 28, no. 6, pp. 2936-2945, 2013.

[16] M. Balato, L. Costanzo, and M. Vitelli, "Chapter 5. DMPPT PV system: modeling and control techniques," in Advances in Renewable Energies and Power Technologies, I. Yahyaoui, Ed., pp. 163-205, Elsevier, 2018.

[17] C. Olalla, C. Deline, D. Clement, Y. Levron, M. Rodriguez, and D. Maksimovic, "Performance of power-limited differential power processing architectures in mismatched PV systems," IEEE Transactions on Power Electronics, vol. 30, no. 2, pp. 618-631, 2015.

[18] M. Vitelli, "On the necessity of joint adoption of both distributed maximum power point tracking and central maximum power point tracking in PV systems," Progress in Photovoltaics: Research and Applications, vol. 22, no. 3, pp. 283-299, 2012.

[19] R. C. N. Pilawa-Podgurski and D. J. Perreault, "Submodule integrated distributed maximum power point tracking for solar photovoltaic applications," IEEE Transactions on Power Electronics, vol. 28, no. 6, pp. 2957-2967, 2013.

[20] D. La Manna, V. Li Vigni, E. R. Sanseverino, V. Di Dio, and P. Romano, "Reconfigurable electrical interconnection strategies for photovoltaic arrays: a review," Renewable and Sustainable Energy Reviews, vol. 33, pp. 412-426, 2014.

[21] M. Balato, L. Costanzo, and M. Vitelli, "Optimization of both the energetic efficiency and the duration of life of PV arrays by means of the dynamical reconfiguration of PV modules connections," in 2015 Tenth International Conference on Ecological Vehicles and Renewable Energies (EVER 2015), pp. 1-6, Monte Carlo, Monaco, March-April 2015.

[22] D. Nguyen and B. Lehman, "An adaptive solar photovoltaic array using model-based reconfiguration algorithm," IEEE Transactions on Industrial Electronics, vol. 55, no. 7, pp. 2644-2654, 2008.

[23] M. Balato, L. Costanzo, and M. Vitelli, "Series-parallel PV array re-configuration: maximization of the extraction of energy and much more," Applied Energy, vol. 159, pp. 145$160,2015$.

[24] H. Obane, K. Okajima, T. Oozeki, and T. Ishii, "PV system with reconnection to improve output under nonuniform illumination," IEEE Journal of Photovoltaics, vol. 2, no. 3, pp. 341-347, 2012.

[25] M. Balato, L. Costanzo, and M. Vitelli, "Multi-objective optimization of PV arrays performances by means of the dynamical reconfiguration of PV modules connections," in 2015 International Conference on Renewable Energy Research and Applications (ICRERA), pp. 1646-1650, Palermo, Italy, November 2015.

[26] C. Olalla, D. Maksimovic, C. Deline, and L. MartinezSalamero, "Impact of distributed power electronics on the lifetime and reliability of PV systems," Progress in Photovoltaics: Research and Applications, vol. 25, no. 10, pp. 821-835, 2017.

[27] P. S. Shenoy, K. A. Kim, B. B. Johnson, and P. T. Krein, "Differential power processing for increased energy production and reliability of photovoltaic systems," IEEE Transactions on Power Electronics, vol. 28, no. 6, pp. 2968-2979, 2013.

[28] C. Olalla, M. Hasan, C. Deline, and D. Maksimović, "Mitigation of hot-spots in photovoltaic systems using distributed power electronics," Energies, vol. 11, no. 4, p. 726, 2018.

[29] S. Roy, M. K. Alam, F. Khan, J. Johnson, and J. Flicker, "An irradiance-independent, robust ground-fault detection scheme for PV arrays based on spread spectrum time-domain reflectometry (SSTDR)," IEEE Transactions on Power Electronics, vol. 33, no. 8, pp. 7046-7057, 2018.

[30] M. Dhimish, V. Holmes, B. Mehrdadi, and M. Dales, "Comparing Mamdani Sugeno fuzzy logic and RBF ANN network for PV fault detection," Renewable Energy, vol. 117, pp. 257274, 2018.

[31] M. Balato, L. Costanzo, and M. Vitelli, "Reconfiguration of PV modules: a tool to get the best compromise between maximization of the extracted power and minimization of localized heating phenomena," Solar Energy, vol. 138, pp. 105-118, 2016.

[32] C. Chamberlin, M. A. Rocheleau, M. W. Marshall, A. M. Reis, N. T. Coleman, and P. A. Lehman, "Comparison of PV module performance before and after 11 and 20 years of field exposure," in 2011 37th IEEE Photovoltaic Specialists Conference, pp. 101-105, Seattle, WA, USA, June 2011.

[33] P. Sánchez-Friera, M. Piliougine, J. Peláez, J. Carretero, and M. Sidrach de Cardona, "Analysis of degradation mechanisms of crystalline silicon PV modules after 12 years of operation in southern Europe," Progress in Photovoltaics: Research and Applications, vol. 19, no. 6, pp. 658-666, 2011.

[34] K. A. Kim and P. T. Krein, "Photovoltaic hot spot analysis for cells with various reverse-bias characteristics through electrical and thermal simulation," in 2013 IEEE 14th Workshop on Control and Modeling for Power Electronics (COMPEL), pp. 1-8, Salt Lake City, UT, USA, June 2013.

[35] F. Fertig, S. Rein, M. Schubert, and W. Warta, "Impact of junction breakdown in multi-crystalline silicon solar cells on hot-spot formation and module performance," in 26th European Photovoltaic Solar Energy Conference and Exhibition, pp. 1168-1178, Hamburg, Germany, September 2011.

[36] Q. Zhang and Q. Li, “Temperature and reverse voltage across a partially shaded Si PV cell under hot spot test condition," in 2012 38th IEEE Photovoltaic Specialists Conference, pp. 13441347, Austin, TX, USA, June 2012.

[37] M. Dhimish, V. Holmes, P. Mather, and M. Sibley, "Novel hot spot mitigation technique to enhance photovoltaic solar panels output power performance," Solar Energy Materials and Solar Cells, vol. 179, pp. 72-79, 2018.

[38] P. Guerriero, L. Piegari, R. Rizzo, and S. Daliento, "Mismatch based diagnosis of PV fields relying on monitored string currents," International Journal of Photoenergy, vol. 2017, Article ID 2834685, 10 pages, 2017.

[39] "Datasheet," http://photonsolar.in/pdfdocs/pm0020.pdf.

[40] "Datasheet," https://www.ht-instruments.it/it-it/prodotti/foto voltaico/misuratori-curva-i-v/i-v400w/.

[41] M. Herman, M. Jankovec, and M. Topič, "Optimal $I$ - $V$ curve scan time of solar cells and modules in light of irradiance level," International Journal of Photoenergy, vol. 2012, Article ID 151452, 11 pages, 2012.

[42] N. Samano, J. A. Padilla-Medina, and N. Vázquez, "Characterization of photovoltaic panels by means of thermograph analysis," International Journal of Photoenergy, vol. 2016, Article ID 8560728, 7 pages, 2016.

[43] "Datasheet," http://www.kepcopower.com/support/opmanls. htm\#bop.

[44] "Datasheet," http://www.testo350.com/downloads/881/testo\% 20881\%20Instruction\%20Manual.pdf.

[45] E. Kaplani, "Detection of degradation effects in field-aged cSi solar cells through IR thermography and digital image 
processing," International Journal of Photoenergy, vol. 2012, Article ID 396792, 11 pages, 2012.

[46] M. Dhimish and V. Holmes, "Fault detection algorithm for grid-connected photovoltaic plants," Solar Energy, vol. 137, pp. 236-245, 2016.

[47] A. Triki-Lahiani, A. Bennani-Ben Abdelghani, and I. SlamaBelkhodja, "Fault detection and monitoring systems for photovoltaic installations: a review," Renewable and Sustainable Energy Reviews, vol. 82, pp. 2680-2692, 2018.

[48] S. R. Madeti and S. N. Singh, "Monitoring system for photovoltaic plants: a review," Renewable and Sustainable Energy Reviews, vol. 67, pp. 1180-1207, 2017.

[49] S. Daliento, A. Chouder, P. Guerriero et al., "Monitoring, diagnosis, and power forecasting for photovoltaic fields: a review," International Journal of Photoenergy, vol. 2017, Article ID 1356851, 13 pages, 2017.

[50] Y. Hu, W. Cao, J. Ma, S. J. Finney, and D. Li, “Identifying PV module mismatch faults by a thermography-based temperature distribution analysis," IEEE Transactions on Device and Materials Reliability, vol. 14, no. 4, pp. 951-960, 2014.

[51] B. Senitzky and P. D. Radin, "Effect of internal heating on the breakdown characteristics of silicon $p-n$ junctions," Journal of Applied Physics, vol. 30, no. 12, pp. 1945-1950, 1959.

[52] I. Geisemeyer, F. Fertig, W. Warta, S. Rein, and M. C. Schubert, "Prediction of silicon PV module temperature for hot spots and worst case partial shading situations using spatially resolved lock-in thermography," Solar Energy Materials and Solar Cells, vol. 120, Part A, pp. 259-269, 2014.

[53] S. Armstrong and W. G. Hurley, "A thermal model for photovoltaic panels under varying atmospheric conditions," Applied Thermal Engineering, vol. 30, no. 11-12, pp. 1488-1495, 2010. 

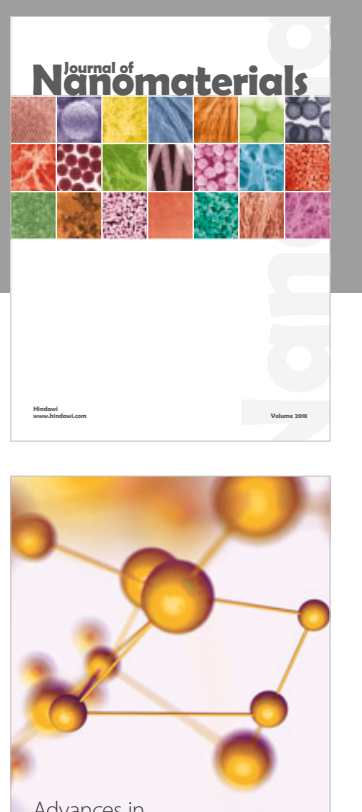

Physical Chemistry
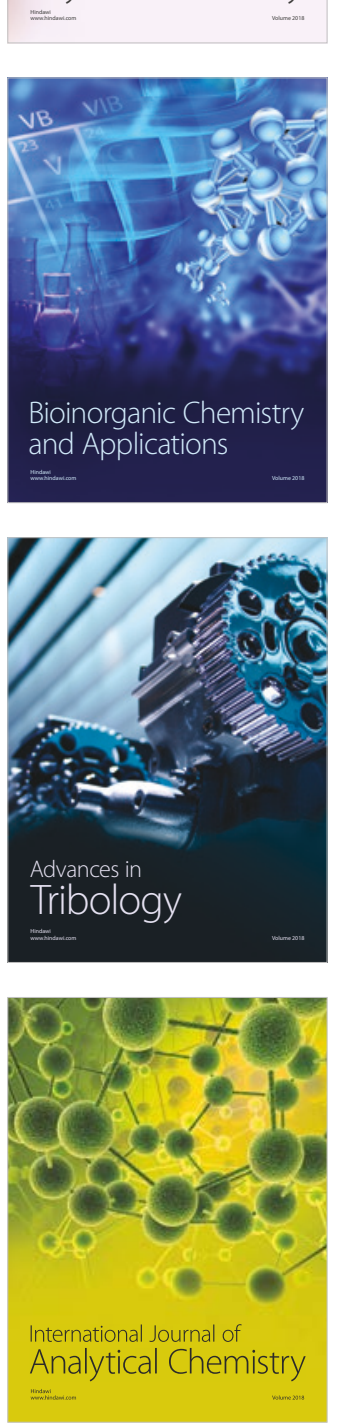

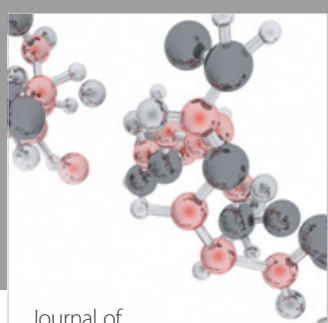

Analytical Methods

in Chemistry

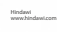

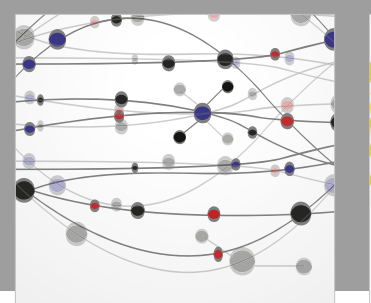

The Scientific World Journal

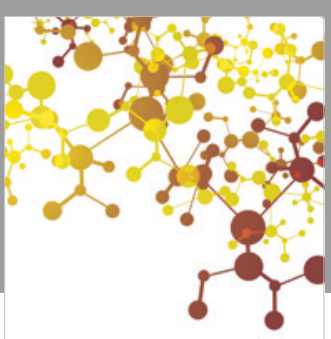

Journal of

Applied Chemistry
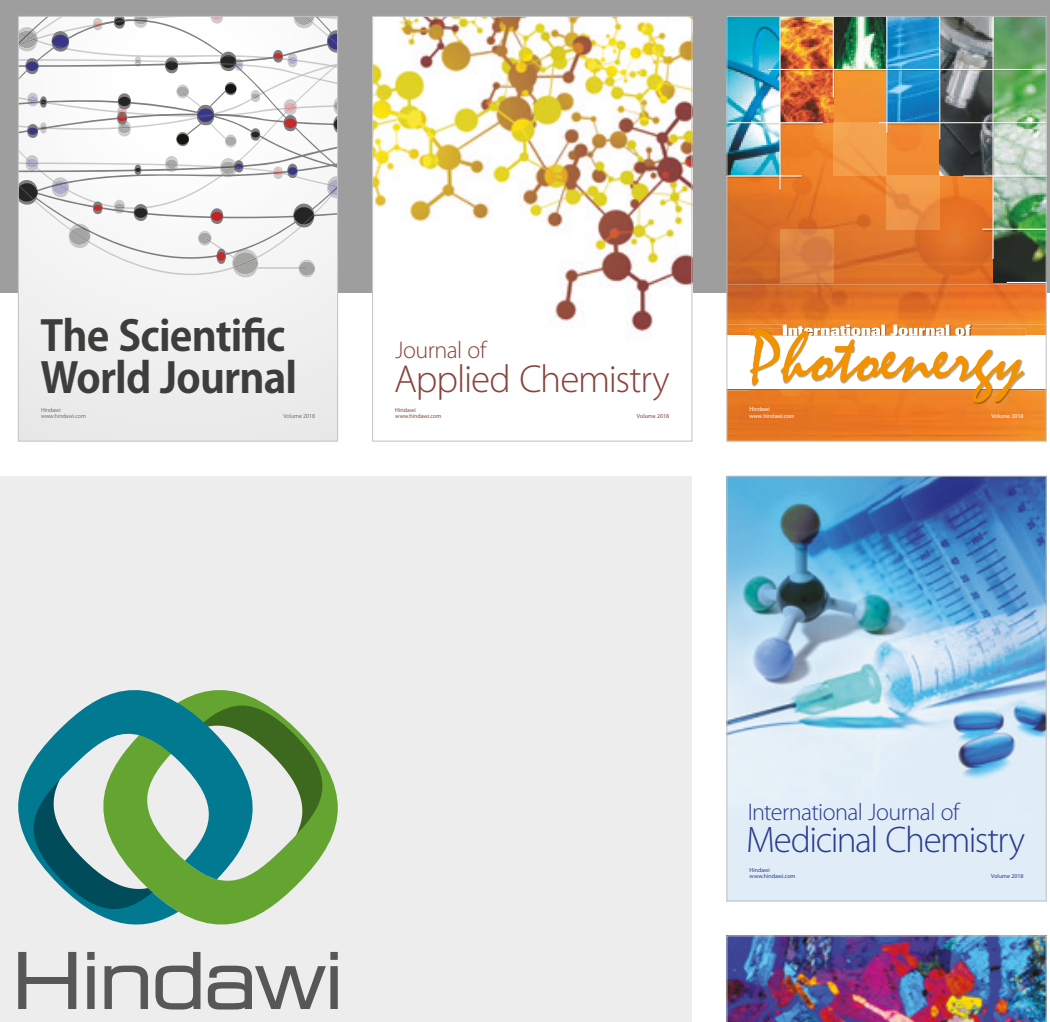

Submit your manuscripts at

www.hindawi.com
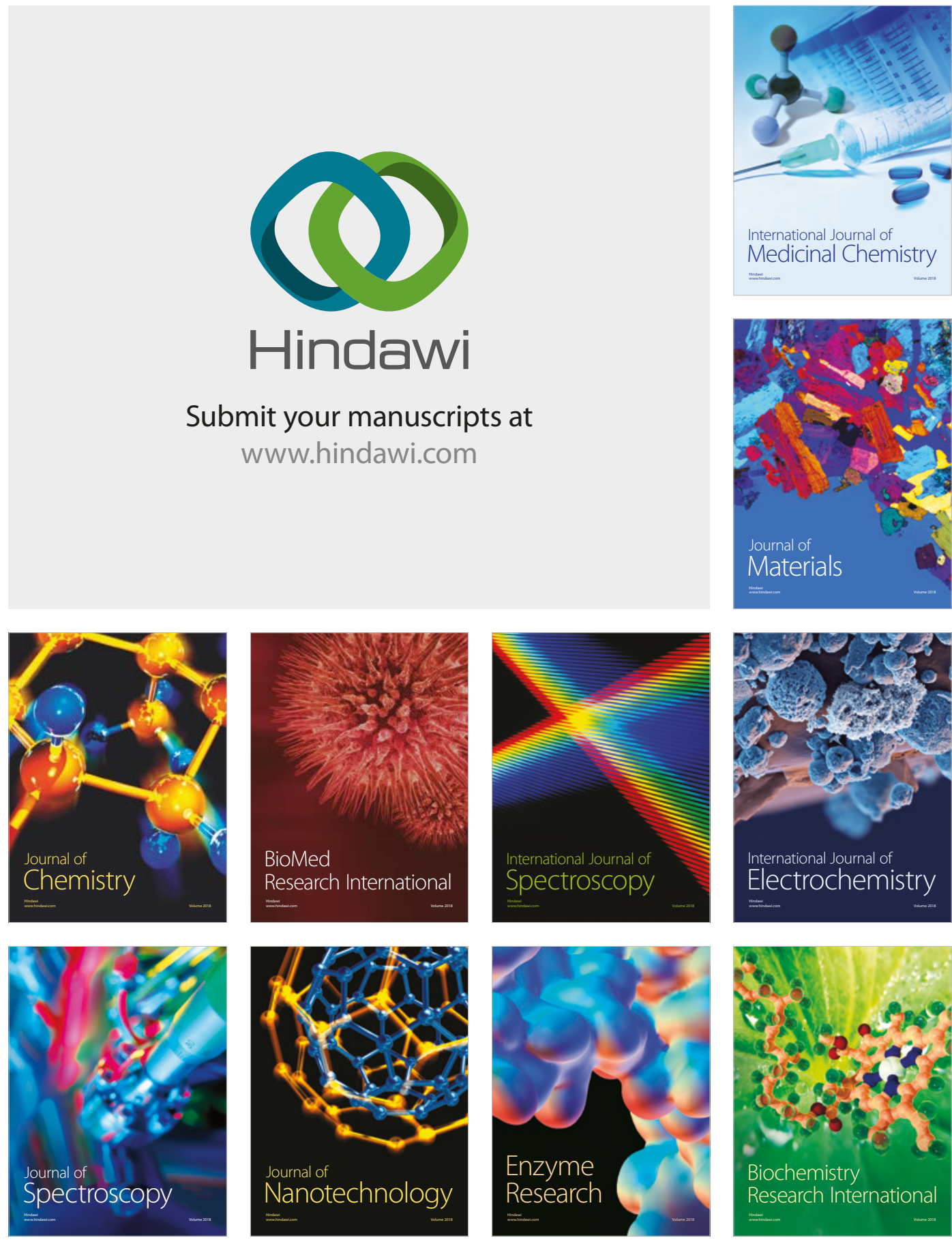
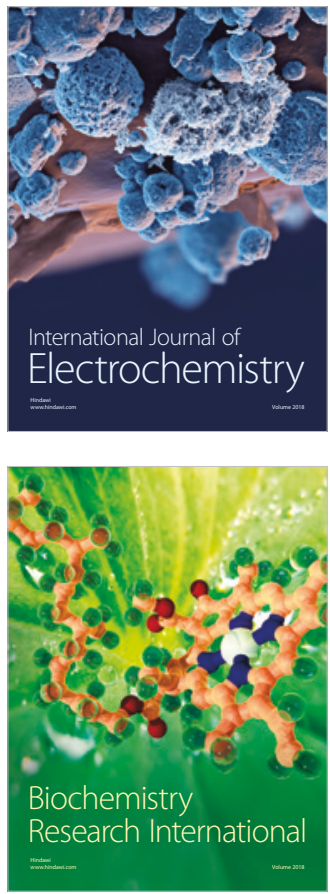